\title{
Laurence Tibi, La Lyre désenchantée L'instrument de musique et la voix humaine dans la littérature française du XIX siècle
}

Isabella Giovinazzo

\section{(2) OpenEdition \\ 1 Journals}

\section{Edizione digitale}

URL: https://journals.openedition.org/studifrancesi/41001

DOI: $10.4000 /$ studifrancesi. 41001

ISSN: 2421-5856

\section{Editore}

Rosenberg \& Sellier

\section{Edizione cartacea}

Data di pubblicazione: 1 juillet 2004

Paginazione: 213

ISSN: 0039-2944

\section{Notizia bibliografica digitale}

Isabella Giovinazzo, «Laurence Tibi, La Lyre désenchantée L'instrument de musique et la voix humaine dans la littérature française du XIX siècle», Studi Francesi [Online], 142 (XLVIII | I) | 2004, online dal 30 novembre 2015, consultato il 09 septembre 2021. URL: http://journals.openedition.org/studifrancesi/ 41001 ; DOI: https://doi.org/10.4000/studifrancesi.41001

Questo documento è stato generato automaticamente il 9 septembre 2021.

\section{cc) (†) $\odot$}

Studi Francesi è distribuita con Licenza Creative Commons Attribuzione - Non commerciale - Non opere derivate 4.0 Internazionale. 


\title{
Laurence Tibi, La Lyre désenchantée L'instrument de musique et la voix humaine dans la littérature française du XIX siècle
}

\author{
Isabella Giovinazzo
}

\section{NOTIZIA}

LAURENCE TIBI, La Lyre désenchantée L'instrument de musique et la voix humaine dans la littérature française du XIX siècle, Collection. Romantisme et modernité, Paris: Champion 2003, pp. 613.

1 Il saggio analizza la rappresentazione poetica dello strumento musicale e della voce nel corso del XIX secolo, cogliendo nelle trasformazioni dei modi di rappresentazione del suono e delle sue fonti, così come negli strumenti che diventano oggetto di poesia, il riflesso dell'evoluzione estetica del secolo, dal Romanticismo al Simbolismo. Il riferimento alla musica, sia nelle forme che negli oggetti è infatti una costante nella letteratura e costituisce peraltro motivo di interesse poiché dimostra la necessità del discorso poetico di cercare appoggio nelle altre arti, come la pittura e la stessa musica.

2 La prima parte dello studio, (L'antécédence de la voix) dedicata alla prima metà del secolo, mette in luce come la rappresentazione dello strumento musicale si ispiri essenzialmente alla voce umana, che gode di un primato cronologico, semiologico, ontologico e metafisico, assumendo un valore secondario rispetto alla voce stessa e alla sua fonte, umana o divina; l'esempio più rappresentativo di questa concezione è secondo l'A. quello di Lamartine, che utilizza la lira come simbolo del suo io poetico.

3 Alcuni strumenti come l'arpa o l'organo, ai quali è dedicata la seconda parte del volume (La Vogue littéraire de l'instrument de musique au temps du romantisme), assumono però un ruolo più significativo e autonomo poiché ad essi viene associata una dimensione sacra 
e trascendente: si tratta di strumenti che sembrano mettere in comunicazione l'uomo con l'Assoluto, identificato con il Dio trascendente o con la natura.

4 Tale dimensione viene totalmente eliminata dopo la metà del secolo, con la transizione dal Parnasse al Simbolismo (Instrument et voix dans la deuxième moitié du siècle: nouvelles orientations); alcuni poeti, tra i quali Rimbaud, eliminano la funzione sacra di organi e campane; Corbière e Laforgue introducono strumenti molto più umili, come ad esempio l'organo di Barberia, i cui ritmi ripetitivi e le dissonanze sembrano riprodotti dalla poesia stessa. Nell'opera di Mallarmé, lo strumento musicale, liberato da ogni connotazione teologica, ma anche dalla sua dimensione sensoriale, assume una funzione metapoetica, diventando rappresentazione dell'ideale dell'autonomia del linguaggio poetico tanto dal soggetto che dall'oggetto della poesia e della sua assoluta priorità rispetto alla realtà oggettiva. 